\title{
Creating opportunities for temporary disconnection: How tourism professionals provide alternatives to being permanently online
}

Convergence: The International

Journal of Research into

New Media Technologies

202I, Vol. 27(6) 163I-1647

(C) The Author(s) 2021

\section{(c) (i)}

Article reuse guidelines:

sagepub.com/journals-permissions DOI: 10.1 I77/|35485652। I 033385 journals.sagepub.com/home/con @SAGE

\section{Christian Schwarzenegger}

Department of Meda, Knowledge and Communication, University of Augsburg, Augsburg, Germany

\section{Christine Lohmeier}

Communication, University of Salzburg, Salzburg, Austria

\begin{abstract}
The ongoing normalization of digital connection has also increased the interest in digital disconnection research. The desire to disconnect is typically considered a critical reaction to the peculiar affordances and prerequisites of fully participating in digital society. While social and political potentials of disconnections as well as reasons to turn away from media are explored in various trajectories, we still know relatively little about the "what then" and "what else" of digital disconnection. In this article, we address this gap and investigate what stories are told and which imaginaries are invoked in order to commodify disconnection in an exemplary field of the growing disconnection industry, namely tourism. Drawing from interviews and analysis of online representations, we analyze how tourist marketers and accommodation providers in the Austrian province of Salzburg are communicating why people should use their vacation to disconnect and what they can expect to find once they are disconnected. Following our analysis, we identify three general themes of how disconnection is countered to living in deeply mediatized and highly connective times: (I) nature and authenticity, (2) (re-)connecting with the self, finding balance, and (3) connection to family/friends/local people. We conclude by discussing the broader implications of our analysis and what the identified ambivalences of disconnection suggest for further advancing disconnection research in the future.
\end{abstract}

\section{Keywords}

disconnection, tourism, nostalgia, nature, digital detox, Salzburger Land

\section{Corresponding author:}

Christine Lohmeier, Department of Communication, University of Salzburg, Salzburg, 5020, Austria.

Email: christine.lohmeier@sbg.ac.at 


\section{Introduction}

Nearly permanent and ubiquitous connectivity through digital mobile technologies and social media is a given for many people. Pervasive digital technologies and digital media communication have become "a dominating nuisance interfering in our lives" (Karppi, 2018: 4), to some, and part of a new normal for others (Vorderer et al., 2018). The ongoing normalization of digital connection has also increased the interest in digital disconnection research. The desire to disconnect is typically considered a critical reaction to the peculiar affordances and prerequisites of fully participating in digital society. Disconnection in this regard has found attention either as a form of a rather collective and political engagement with the imperatives of hyperconnected capitalist societies or as a rather personalized and individualized form of self-care directed toward personal well-being. Either form of disconnection has been subject to commodification in recent years, exploiting the collective appeal and deriving disconnection of its critical potential by transforming into a commodity and lifestyle choice (Kaun and Treré, 2020; Natale and Treré 2020).

While social and political potentials of disconnections as well as reasons to turn away from media are explored in various trajectories, we still know relatively little about the "what then" and "what else" of digital disconnection: Until now, the experiences promised for the time after the plug is pulled and for during the disconnection episodes are understudied and less emphasis has been put on investigating the imaginations, ambitions, and longings of where to turn to and what to connect with, when disconnecting from digital technologies and digitally molded lifestyles. In this article, we address this gap and investigate what stories are told and which imaginaries are invoked in order to commodify disconnection in an exemplary field of the growing disconnection industry, namely tourism. Tourism promises an emblematic case for understanding how the desires and goals of what to achieve and experience during disconnection or as a result of unplugging are communicated to potential customers. The expectations put into a tourist experience reach beyond finding affordable or luxurious accommodation, delicate food and an opportunity to visit places of interest. Tourism is a particular branch in which the idea of living an alternative to the everyday and allowing for a temporary break from daily routines and stressful affordances is part of the commodity. It is long since an area specialized in commodifying "fantasy worlds," which can be consumed and experienced "promising entry for a short while into an existence far removed from the humdrum of everyday life" (Cooper, 1994). When digital connectivity has become an increasingly normal part of everyday life, and in some cases a source of stress and strain, digital disconnection can become an element of the antidote to the everyday sought during vacation. What it can mean to experience a digital-free holiday then becomes part of the image that is used to sell tourist experiences.

Indeed, digital-free tourism is not only a recent development, but has been discussed as one of the future trends in tourism for several years and in particular in the context of wellness and mindfulness offerings (Syvertsen, 2020). Digital-free tourism is increasingly pursued for goals of health and well-being and other wellness offerings, in particular stress management and support for work-life balance. In this study, we ask how tourism providers aim to create images of digitally disconnected alternative spaces and times and what images and ideas of spending disconnected time are invoked by tourism providers. Analyzing the visions used to invoke fantasy alternatives to the everyday allows understanding prevalent ideas of how digital connection is normalized as a characteristic of living in our times, and what aspects of connectivity are problematized through the (re)presentation of what kind of experiences should be restored or strived for instead. Ironically, we study these visions and imaginaries of disconnection as they are represented in online communication: Digital media and in particular social media have become a vital factor in the construction of tourist destination images (Wacker and Groth, 2020). Instagram is the most visual among nowadays social 
media platforms and has been paramount for the development of current visual social media aesthetics and the digital social media culture of our age (Leaver et al., 2020). In this capacity, Instagram has also become crucial for the representation of tourist destinations, the touristic marketing of illusions, and recounts of tourist experiences afterward. Drawing an analysis of online representations (Instagram and websites) in combination with interviews, we analyze how tourist marketers and accommodation providers in the Austrian province of Salzburg are communicating why people should use their vacation to disconnect and what they can expect to find once they are disconnected. Specifically we ask:

1. What are tourism professionals' views of disconnection in a deeply mediatized world, characterized by the quasi-omnipresence of digital communication and digital devices in nearly all social domains?

2. How do they address disconnecting in their offers? What are their experiences of visitors disconnecting?

3. What do tourism professionals guide guests toward when they disconnect?

Doing so, we particularly emphasize the role of nostalgia in the imaginaries of disconnected lives (during vacation) employed by tourism professionals. In line with previous research (Schwarzenegger and Menke, 2021), we assume that nostalgic images of the good old days without an abundance of digital noise and the need to connect are used to idealize and romanticize experiences away from digital devices. Following our analysis, we identify three general themes of how disconnection is countered to living in "an age of constant connectivity" (Ytre-Arne et al., 2020): (1) nature and authenticity, (2) (re-)connecting with the self, finding balance, and (3) connection to family/friends/local people. First, we discuss tropes and trends of disconnection research and how being disconnected was transformed from being a fallacy to becoming a luxury. We then review literature on reasons why people disconnect and discuss the role of mindfulness and nostalgia in this context. This is followed by the presentation of our case, the Salzburger Land, our methodological approach and presentation of our key findings. We conclude by discussing the broader implications of our analysis and some of the identified ambivalences the commodification of disconnection makes visible.

\section{Literature review}

Digital disconnection - from the disadvantage of have-nots to the privileged luxury of choice. Research into the non-use of digital media, following Bucher (2020), can be differentiated in more traditional approaches to involuntary and in more recently addressed voluntary forms of disconnection.

Involuntary forms are reflected in studies on digital divides and social inequalities, often pathologizing non-use through a "clinical eye" as a consequence of disadvantageous individual and social dispositions (Selwyn, 2003). In this trajectory, the non-use of technology equates limited participation possibilities in the digital society and is hence considered detrimental. In this strand of discourse providing access, skills, or means to the digital have-nots is deemed imperative for overcoming inequalities (Hesselberth, 2018). Availability, accessibility, and ability to use digital media indicate privilege and opportunity to participate in society.

Research into voluntary forms of disconnection on the contrary typically considers disconnection as an active choice of resistance or experience of empowerment (Bucher, 2020). The study of (more or less) voluntary digital disconnection has so far strongly focused on the "why's" and "how's" of 
disconnection practices from a (non-)user's perspective, experiences made and their consequences. These were addressed either on the level of individuals and their personal motives to abstain or refuse or as part of a collective group action, for example, as an articulation of political discontent or a lifestyle choice (Kaun and Treré, 2020; Morrison and Gomez, 2014). In this vein, also organized offerings like particular retreats for the purpose of detoxing and disconnecting from an overload with digital media were explored (Fish, 2017; Sutton, 2017; Syvertsen, 2020). We see this latter trend of increased (academic) interest in voluntary disconnection practices as indicative of two relevant developments. First, the growing wish for disconnection, digital detoxification practices, and similar forms to meaningfully disconnect from a perceived abundance of digital connectivity signals that digital connection has indeed become a rather widespread and pervasive feature of the everyday. Permanent connection is affordable to many, rendering digital availability into an expectation and norm. Rather than not finding access to the digital technologies, inequality of people now partially manifests as a result of personal or professional dependencies and responsibilities in their lives, which do not allow them to evade from being digitally available. Second, by normalizing the idea of connection as a somewhat natural state and disconnection as a temporary escape from the norm, it is disconnection that becomes an attainable good, which is not available and affordable to everyone. Being in a position to voluntarily disconnect becomes indicative of autonomous disposal over your time and the privilege of choice. In this regard, Kaun and Treré (2020) have described disconnection as a lifestyle option and a way to distinguish oneself from "ordinary" others. The ability to choose to disconnect and abstain from the media in times when permanent availability and connection are allegedly expected can symbolize autonomy, control, and a particular connoisseurdom - disconnection can become a luxury indeed.

The experience of disconnection as a privileged choice is increasingly subject to commodification: Being offline as a new luxury is marketed in a variety of products and accessories "suggestive of disconnection" (Jorge, 2019), as exclusive touristic experiences, and also in the form of technological solutions and apps, which help endure and reward disconnected time. The obvious paradox of promoting digital devices or applications as enablers of digital disconnection makes visible that digital disconnection as a commodity is not meant to propose a real or lasting alternative to digital lives, but rather provide a temporary retreat, which ultimately reinforces that connection is the norm. Similarly, also other offerings that present digital disconnection as a commodity are meant for a passing moment and not permanently. In this respect, it is only consequential that "Disconnect to reconnect" (Sutton 2017) has become an emblematic slogan for the commodification of the digital detox idea and is used to advertise detox retreats and tourist attractions. As Natale and Treré (2020:3) have noted:

\footnotetext{
"This slogan points to the key contradiction at the heart of contemporary disconnection. It evokes a nostalgic idea of a 'locus amoenus' where, free from the pressure of digital technology, we can finally experience a form of superior reconnection to a primordial state of nature. At the same time, it should be taken literally as an experience of disconnection leading to reconnection."
}

Furthermore, studies have also found that experiences during a digital detox episode or temporary voluntary abstention from online environments can become relevant for self-presentation on social media (Schwarzenegger and Menke, 2020): Digital disconnection becomes a resource for content to share after an offline period, and disconnection is consumed with the reconnection in mind. So quite ironically, practices and commodities idealizing and romanticizing disconnection hence become integral parts of social media connectivity and allow for insights into what is emphasized and highlighted as the motivation or cause for or positive experience and consequence 
of a disconnection episode. Jorge (2019) focused on such recounts of digital disconnection experiences on Instagram. In her analysis she differentiates three different yet intertwined types: (1) Accounts of disconnection by users who had gone through a voluntary offline period or phase of digital detox and praised the positive experience of mindfulness, autonomous time control, and positive results on their personal health. (2) Users heavily advertising for disconnection practices and promoting ideas of disobediences to the technological imperatives of their devices, with an ambition of converting others. As a third type, (3) Jorge found content treating disconnection practices as a lifestyle choice and as marketing strategy or commodity. All three types of content revolve around certain cultural and collective imaginations of what is to be gained through disconnection and conversely also ideas of what is lost or under peril due to ubiquitous digital media. Typically, the use of digital media — echoing discourses regarding previous media technologies - is considered too time intensive, potentially a waste of time. Time away from the media, in contrast, could allegedly be spent more meaningful, with other activities, in particular to be in nature or for maintaining social relationships with friends and families (Allcott et al., 2020; Gomez et al., 2015). In line with that, visual representations of disconnection: "unplugging from technology and returning to nature are presented as an antidote to information overload" (Gomez et al., 2015). Relatedly, but coming the other way, Pentzold et al. (2020) in their analysis of the hashtag \#qualitytime on Instagram found that in the images and ideas shared under this label, mobile phones and social media were "conspicuously absent," that is, that quality time was imagined as a time without media.

These findings, based on social media analyses, are also supported by studies on users and their motives for digital abstention. Time without digital connection is often considered as a more real experience, as time for themselves or quality time (Schwarzenegger and Menke, 2020). Having meaningful and authentic experiences, regaining control, and temporal autonomy as well as improving health or well-being are among the recurrent reasons for disconnecting (Baym et al., 2020; Schwarzenegger and Menke, 2020; Sutton, 2017). The promise of finding advantages for the personal well-being and also therapeutic benefits through a period of abstention was also among the hopes and goals users disconnecting from digital media voiced as part of their motivation (Hardey and Atkinson, 2018). Kaun and Schwarzenegger (2014) in their qualitative forced disruption experiment found that their study participants were vocal about similar reasons why to abstain from the use of digital media - most prominently to avoid pressures of technology use and make more meaningful use of their time, but at the same time the participants struggled to describe what this better use of time could be or what they pictured as offline-time well spent. The authors concluded that while there is a strong shared sentiment that screen-time or time spent with digital devices may have negative impact on their overall well-being, productiveness, or sociality, when it came to imagine what to do without, many of them restrained to clichés of family life and social bonding, but without much nuance and lacking detailed ideas for the time without media. So far, studies on the commodification of disconnection (aside from social media representations and detoxification apps) are scarce, and the providers of such offerings and their reasoning are yet to be explored. However, user expectations and social media representations appear to mirror broader and historically persistent cultural narratives of time without media use being more precious time and conjure up nostalgic ideas of a time when people allegedly had more genuine feelings and more real experiences with each other because they were not constantly stuck in digital expectation. It is hence fair to assume that these imaginaries will also resonate in professional tourist representations of digital disconnection. But what images and ideas of time away from digital devices and connections are invoked to advertise the experience away from the everyday? 


\section{Disconnection and nostalgia: Longing for a place that never was}

Digital detox or the wish to disconnect from digital media abundance is often linked to nostalgic stencils and the past, or rather alternative nostalgic versions of the past, provide rich inspiration for why to disconnect. According to Syvertsen and Enli (2019), the wish to disconnect can be triggered by a nostalgic longing for a past, when people allegedly had more time on their hands, a more defined space, and a less stressful lifestyle. Nostalgia serves "as a template for a better use of time without media, in nature with family and friends, marking real experiences instead of virtual ones" (Schwarzenegger and Menke, 2020: 73). As mentioned above, the accounts of what to do in the disconnected time lack nuance and detail. The nostalgic longing for "a better tomorrow in the yesterday" (Menke and Schwarzenegger, 2016) is often pictured with nostalgic ideas of a past that never was: "Nostalgia (from nostos — return home and algia-longing)." Svetlana Boym explains "is a longing for a home that no longer exists or has never existed (2001, xiii). Nostalgia, as Niemeyer and Keightley recently summarized, is "a recollection of times and places that are no more, no longer accessible or perhaps never were. It can also refer to a desire for a return to a past time that we never experienced or the regret for a past that never was, but that could have been, or for a future that never will be" (Niemeyer and Keightley, 2020: 1641). In this regard, nostalgia for them is located at the intersection between remembrance and forgetting, idealization and creativity (Niemeyer and Keightley, 2020). Boym argued that "Nostalgia is a sentiment of loss and displacement, but it is also a romance with one's own fantasy" (2001, xiii). Following in this trajectory, it is not necessarily the own fantasy alone, but also how shared fantasies and ideas of nostalgic longing are collectivized and then used to create "sites of desire" (McDonnell, 2018) through tourist advertising.

Research has long since established a strong link between tourism and nostalgia (Christou, 2018; Dann, 1997; Shaw, 1992). Tourism has been found exploiting nostalgia and nostalgic sentiments for its economic advantages. The nostalgia and tourism nexus can work in different ways and nostalgia is commodified to enable different kinds of touristic experiences. Besides triggering personal nostalgia and memories, nostalgia for cultural heritage (sites) is among the most established forms. Nostalgia can further be an important carrier of tourism in particular for rural settings, which promise that through physical mobility to a particular touristic spot, the tourist will also be able to traverse time and find the traditional and vintage-charm of how we used to live in the days of old (Christou et al., 2018; Creighton, 1997).

Especially in the Austrian case, nostalgia and tourism can be seen as strongly interrelated and nostalgic sentiment is heavily exploited in the Austrian tourism branch in several ways. For instance, nostalgia for the Habsburg Empire and the heydays of Austrian grandeur as a leading European monarchy resonates strongly in Austrian tourism (Kelley, 2009). This is less a "restorative nostalgia" (Boym, 2001: 49) that really wants to cater to monarchist aspirations, but rather mimics a media imaginary of how Austria used to be and wished to imagine itself since. The Habsburg nostalgia is hence heavily influenced by the popular portrayal of Austria in film and other media (Keller, 2016). In a second way, nostalgia in Austrian tourism caters to what has been described as heritage tourism (Ali, 2015), important and magnificent cultural heritage sites, which are carriers and drivers of the tourist experience. In a third way, Austrian tourism has highlighted the unaltered purity of Austrian nature (Katelieva et al., 2020), especially its impressive mountain sites in the Alps, its forests, and lakesides. This nativeness and purity of nature serve as a stark contrast to modern urbanism and in opposition to industrial anomie of our modern times (Christou et al., 2018; Creighton, 1997). It is in tourism, where the commodification of nostalgia for the old days, for pure nature and pristine lifestyles intertwines with 
imaginaries regarding mindfulness, health and wellness, and digital disconnection as a condition to achieve either.

Digital-free tourism finds attention of the hospitality industry as one of its coming trends already in 2012, as Syvertsen (2020: 5) pointed out. In an analysis of representations of digital-free tourism in media texts published between 2009 and 2017, Li et al. (2018) identify a recent shift in how the topic is addressed. While between 2009 and 2015 digital-free tourism was dominantly represented as a "reaction to the pressures of abundant connectivity," according to them, tourism without digital media is increasingly presented as a choice for an enhanced lifestyle, human flourishing, and wellbeing. The identified media representations are in line with the findings of studies that aimed to identify motives of tourists who seek for digital-free tourism. Egger et al. (2020), for instance, found the aspirations for positive health effects and general well-being as main motives besides escaping from too much connectivity. Contrary to that a majority of studies in tourism assume "connection is a positive thing and an opportunity to be harnessed by the industry that will enhance tourist experiences and business opportunities."(Dickinson et al., 2016: 194). Whereas the desire to "get away from it all", that is, to disconnect and not have to be available for others without a fear of missing out while offline, can be identified as a driver of digital-free tourism offerings and demand, the desire to disconnect is not to be seen as an absolute. Tourists also embrace the benefits of connectivity while abroad; hence, an ambiguity of mobile technology use and digital communication in tourism can be observed. Dickinson et al. (2016) in their study on camping tourists in the UK found tourists to be managing a dilemma between benefitting from the positive functions mobile connectivity can have for the travel experience and avoiding the negative impacts (e.g., intrusion of work, family, or friends, less chance to be in the moment and engage with the natural environment). Tourism providers have to master this ambivalence between a demand for disconnection and not wanting to be rid of amenities during the vacation in the digital and visual representation of their offerings.

In this contribution, we explore the promises made and the hopes encouraged by the growing disconnection industry, particularly in tourism and leisure activities. In particular, we investigate what people willing to disconnect are guided toward by professionals in the tourism industry.

\section{Methodological approach}

Primary data were gathered by employing a qualitative content analysis and semi-structured interviews. Initially, we conducted an online analysis of tourism agencies, hotels, and other accommodation facilities in the Salzburger Land. We approached this by systematically looking at each region of the Salzburger Land and examining their websites and social media content, in particular on Instagram. In tourism research, the analysis of Instagram representations by tourism providers but also by travelers and ordinary media users is used to analyze how particular destinations are perceived by past and potential future travelers through social media, and in how far the images presented and created there are in line or at odds with the representations offered by destination marketing organizations. Social media images have also become important means for the information seeking of would-be tourists. Beyond Instagram's relevance for the study of tourism, the social media platform is also a relevant site for the representation of offline lifestyles, digital detoxing, and disconnection exercises and for the representation of good and meaningful social interaction and bonding in quality time (Jorge, 2019; Pentzold et al., 2020).

Using theoretical sampling, and aiming for a broad variety in the cases under scrutiny, we then selected three tourism agencies and two hotels and one alpine cabin.

Next, we collected text and images used by each of the selected research participants. In particular, we examined texts and images on Instagram feeds and websites to explore how the time 
spent in the region or respectively the hotels/the cabin is constructed. Toward that end, we categorized the overall presentation and individual images and texts by drawing on the visual analysis as outlined by Philippe Viallon (2016). All textual materials - including posts, website copy, and interview transcription-were analyzed in line with the procedures outlined by Fürst et al. (2016). From these, we developed three prevalent themes of (1) nature and authenticity, (2) (re-)connecting with the self, finding balance, and (3) connection to family/friends/local people outlined in the findings below.

We also conducted six semi-structured interviews with executives in tourism marketing and hotel managers in the Salzburger Land. We interviewed three representatives of tourism marketing agencies in the Salzburger Land. These were selected with the diversity of the Salzburger Land in mind; that is, we approached executives in charge of different areas within the federal state. Some areas are more rural with landscapes characterized by large woods, lakes, and mountains, others more urban, so the tourism marketing agencies promote the mixed experience of a city with its museums and cultural events as well as attractions in the natural world. All interview partners lived in the region they represented in their day jobs. Two of them were native Austrians, one was originally from Switzerland and had lived in the region she represented for almost a decade. The interviewees had served in their respective position for a minimum of 5 years. Tourism marketing agencies have a strong affiliation to the region as a whole, as opposed to one specific hotel or guest house. Our questions therefore aimed at getting the tourism marketing perspective of the region, understanding where the majority of guests came from, what their motives were for selecting this particular region of the Salzburger Land. In addition, questions focused on the strategies employed to market the region and the significance tourism executives assign to concepts like "digital detox."

Three further interviews were conducted with hotel or guest house managers based in the Salzburger Land; we included the manager of one alpine cabin with only basic facilities and no internet or mobile connection. We also interviewed the manager of a family-run four-star family/ wellness/fitness hotel in the Pongau region and the manager of another family-run four-star wellness hotel in the Flachgau region. Similar to the themes mentioned above, we also asked the hotel and guest house managers about their perspective on "digital detox" and the specific offers they make in their facilities. Interviews were conducted in December 2020. They lasted between 30 and 45 min and were conducted either face-to-face or using an online conference tool.

\section{The case of the Salzburger Land}

The Land Salzburg is one of nine Austrian federal states. Located in the north east of the country and sharing a border with Bavaria (Germany) in the north, the Salzburger Land consists of six regions. The capital is the city of Salzburg. The Land Salzburg has over half a million inhabitants. The entire state, including the city of Salzburg, is very popular with tourists from neighboring Germany and elsewhere, with around 8 million people visiting per year. A study on the representation and construction of Austrian travel destination images on travel blogs, found Salzburg to be featured most prominently after Vienna (Wenger, 2008). Salzburg, the province under scrutiny in our case study is also scoring high on the Austrian nostalgic tourism scale through links to popular culture, for example, the Sound of Music movies and the remembrance of Wolfgang Amadeus Mozart, who was born in Salzburg and lived there through some of his most prolific periods.

Visitors appreciate the natural beauty of the Alpine landscapes for outdoor activities like hiking, climbing, or skiing during the winter months. In addition, the towns and cities offer a variety of cultural events, such as music festival Salzburger Festspiele. The high number of visitors has greatly benefitted the Land in economic terms. However, especially in the city of Salzburg but also in more 
rural areas, over-tourism is an issue that is discussed repeatedly. These diverging interests are of course absent in representation addressing potential visitors. A quick glance at websites and social media feeds of hotels, spas, and alpine cabins as well as tourist marketing agencies confirms that alluding to nature and displaying the outdoor activities the Land has to offer is a cornerstone of their marketing strategies. As outlined in greater depth in the findings, nature is invoked as a nostalgic counterpart to hyperconnected times. Austria, the country where our case study in the Salzburger Land is located, is identified as a big supplier in the area of health tourism, in particular wellness and spa offerings (Smith and Puczkó, 2015). In line with that there's also a strong focus on well-being, relaxation, and slowing down in our target area.

\section{Nature and meaningful connections as a counterpoint}

The research questions guiding our project aimed at finding more nuanced answers to what people were (assumed to be looking for) and guided toward in phases of disconnection by tourism professionals. We chose to focus our research activities on tourism marketers and providers (instead of tourists) as they have a broader overview regarding demands and offers. Ultimately, it is them who need to invoke and cater the dreams and fantasies of would-be travelers and customers.

With regard to disconnection, mobile phone and media use more generally, the underlying assumption of all interview partners was that less media use is superior to more and frequent use. Their reflections mirrored the persistent cultural imaginary that time away from the media is more gregarious than time invested in media use. As hosts and facilitators of experiences wanting visitors to have a great holiday, our interviewees shared a notion of putting away the mobile phone completely or at least using it less frequently opens up the space for what interviewees framed as more meaningful, deeper, and more nourishing experiences. One interviewee (tourism agency professional) described the area he was marketing as a "refuge-away from everyday life, where you can recharge and resurge, where you get new energy before you go back to your normal life." Another interviewee, a hotel manager, saw it as part of his job to create an environment that allowed and encouraged just that: "[It's about] somehow creating an atmosphere which makes the guest think 'Hey, I'm going to leave my mobile phone in my room. I just don't need it right now. I'm going to read a book or have a deeper conversation with my partner or my family.' I believe it's mainly about creating a feeling that you pass on to the guests [...]" (interview with hotel manager). Creating an atmosphere for our interviewees meant to highlight the alternatives and emphasize what could be done, rather than reminding visitors of what they seek refuge from. Not referring to the everyday is key for getting away from the everyday. All interviewees also shared the idea that getting people to appreciate nature was a key element of encouraging disconnection of visitors and tourists which would ultimately benefit their entire experience. "[This area] where you have these ten to twelve alms - there's just another rhythm of life. You aren't forced to - bam, bam, bam, do this, experience that-but instead you can just be in nature, just as it is." Promoting digital disconnection during the vacation, the tourism providers and marketers in our study show, begins with invisibilizing digital connection in the marketing communication. Communication revolves around "what else" there is to do. In total, we found three recurring and overlapping themes that interviewees referred to: (1) nature and authenticity, (2) (re-)connecting with the self, finding balance, and (3) connection to family/friends/local people. 


\section{Nature and authenticity}

Nature was seen as a counterpoint to the "constant acceleration of everyday life" (interview with tourism marketing professional). Moreover, it was repeatedly framed as real, authentic, and inviting another rhythm of being. "Simply experiencing nature for what it is [...] becomes more significant during the holidays" (interview with tourism marketing professional). Interestingly, the word "nostalgia" is not mentioned once in all interviews conducted. Yet, there is a sense of simplicity and ease described that has been lost in the everyday lives of many. One indicator for this is being available at all times, being up-to-date with regard to the news as well as personal updates from family and friends (Natale and Treré 2020) The alpine cabin manager we interviewed spoke directly to this notion: "Getting away from it all really isn't that easy, I have to say. When you're in the thick of it, it takes effort to pull yourself out of it [always being available]. But when people are up there in the alpine cabin, they notice it's fine and they start to really enjoy it [being offline]. That's where they [guests at the alpine cabin] learn that there is life without a mobile, without being online" (interview alpine cabin manager).

In that sense, the interviews confirm the findings of Christou and colleagues (2018) that the assumed purity and nativeness of nature is conceived as an essential part of the antidote to technostress and the negative consequences of hyper-mediated lives. The images selected for websites and on social media feeds allude to the focus on nature, the promotion of natural beauty and outdoor activities, as shown in the example of the Instagram feed of the Gastein tourism marketing agency (Figure 1).

However, going beyond the supposedly healing qualities of nature, interview partners also pointed toward valuing nature - going for a walk in the woods - and appreciating the authenticity, realness, and the groundedness that could be found outdoors. Nature in combination with disconnection was also constructed as a way to stop pretentiousness and disengage from (unwanted) identities and, instead, to take on a new (or forgotten) persona. This links to and overlaps with the second theme of rediscovering the self.

\section{(Re-)connecting with the self, finding balance}

All interviewees emphasized the benefits of spending time in nature and engaging in outdoor activities: "People appreciate the nature we have here so much. They can go outside, be in nature, experience naturalness [...] There's demand for 'being rooted in the soil. People are searching for that" (interview with tourism marketer, Lungau). In line with the findings of other studies, being outdoors was associated with recharging, finding balance, and slowing down. In their role as hosts and tourist marketers for regions of the Salzburger Land, the interviewees also viewed it as part of their role, to invite and help facilitate this experience. One tourist marketer described his perspective on visitors to the region in the following way: "How are you supposed to do this, finding balance, recharging? You'll never get there. You're at home, your subconscious, your brain's always working. I believe that's why we have to make an offer or provide a product or opportunity. So we say 'Look, you can explore something here [as a tourist in the Salzburger Land] - but with a much greater variety and depth than you ever could at home" (interview with tourism marketing professional). The holiday is seen as an opportunity to not only relax and recharge but also to get to know oneself in a new way. Disconnecting or at least using the mobile phone (and other media) in a different manner than would be the case in everyday life is seen as a prerequisite to unlock the opportunity of reconnecting with the self and getting to know oneself in new ways (Figure 2). 


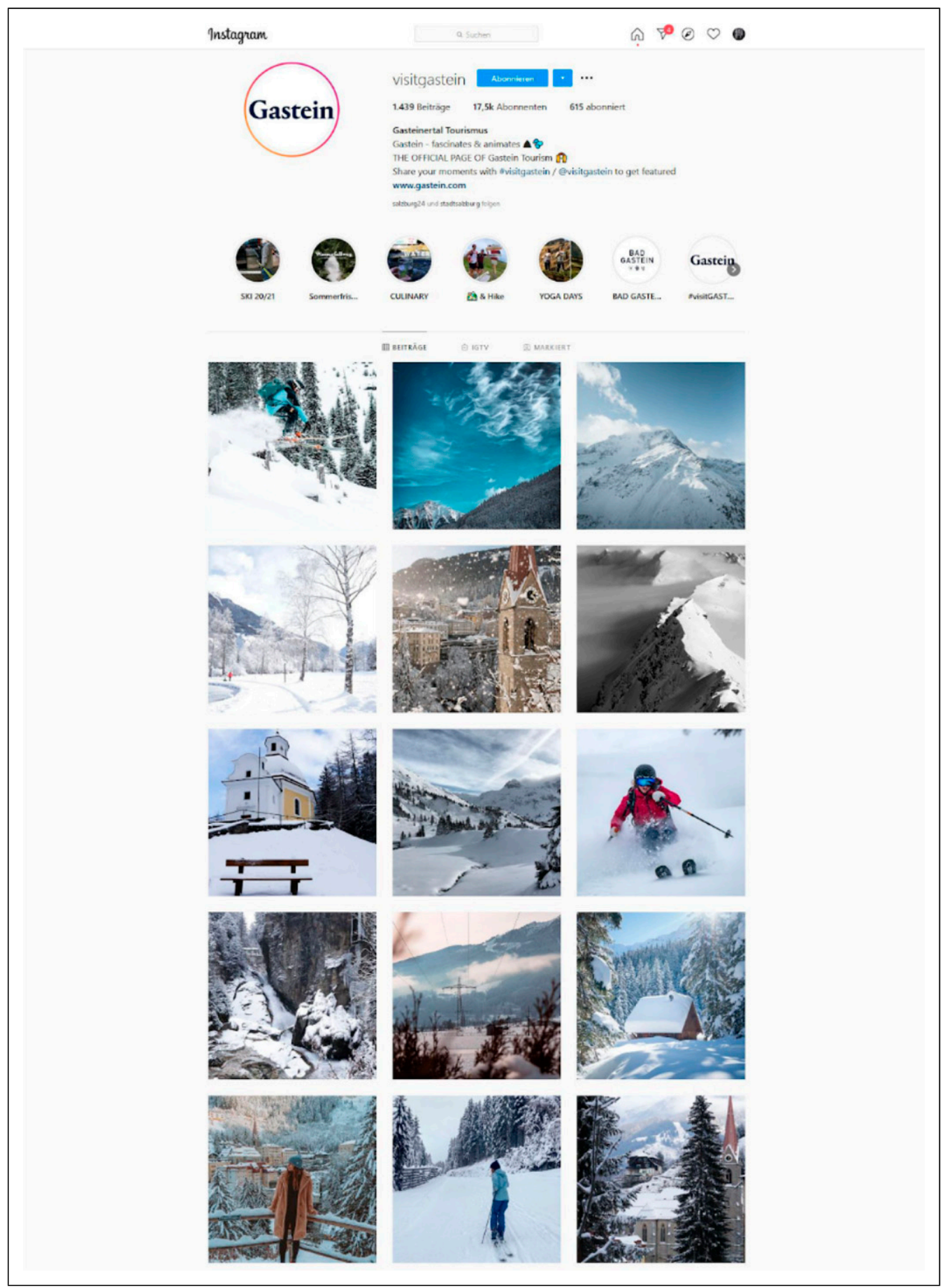

Figure I. Instagram feed of Gasteinertal Tourismus (https://www.instagram.com/visitgastein/). 


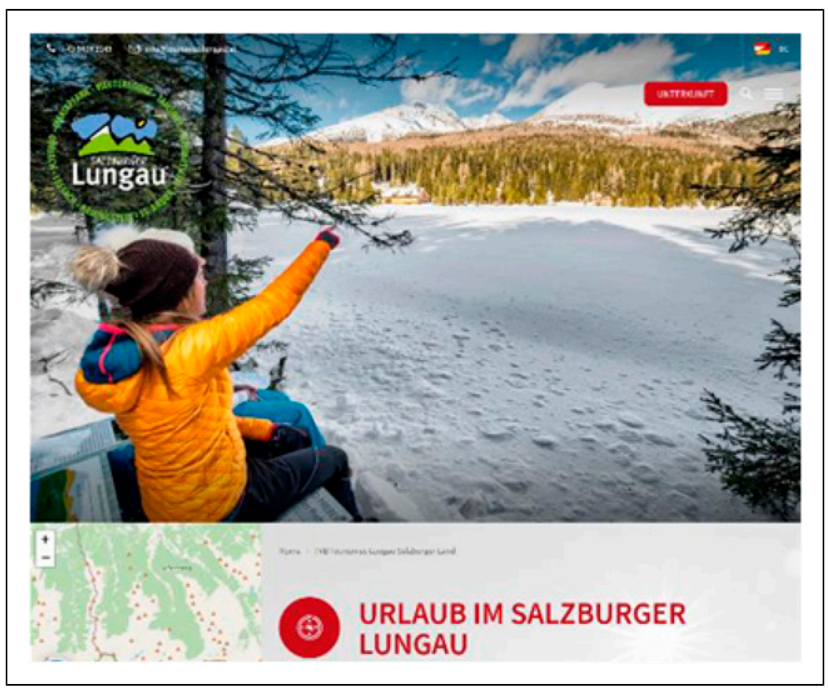

Figure 2. Website of Salzburger Lungau (www.lungau.at).

As the quote above shows, the idea of exploring is directed toward outside and outdoor places and activities. This is where offers such as themed hiking paths or helicopters flights come in. At the same time, the guests are imagined and encouraged to explore themselves and to reconnecting with themselves in a deeper, more mindful way. The link between these inner and outer explorations is sensual experiences, in particular food. A hotel manager we interviewed shared: "I'm such a great fan of local products... we currently have a couple of local [business] partners such as an organic chicken farm or an alpine cabin where they make cheese. We encourage guests to go there for lunch or a light dinner. Or they can just go and visit to have a look where their food comes from." Eating local, eating healthy, experiencing eating and enjoying meals was another significant aspect of reconnecting with the self, exploring while also finding balance. Like all themes presented here, we found a great resonance between the visual material and the interview data. These resonances also underlined the significance of the recurring themes identified, for example, Figure 3 with images of a typical cabin meal, the making of local cheese and locals planting a tree together underlines the value of food, local produce, and close connection to nature that was also highlighted in the interviews.

\section{Connection to family/friends/local people}

The material we analyzed was highly ambivalent regarding the topic of connecting to family and friends. On the one hand, spending time with the partner, family, and friends who were experiencing the holiday together in person was rated as a positive outcome of a holiday. On other hand, connecting to family and friends at home (through digital devices) was seen as creating an obligation to react, engage, and connect. Perhaps not surprisingly, face-to-face communication was valued much higher. It was also perceived as true, deep connection that allows for meaningful sociability. Drawing on her own holiday experience, one of the interviewees was nostalgic for times when there were no means of finding out immediately what was going on at home: "Being constantly connected to the family at home is convenient, but it's almost like you can't get away. 


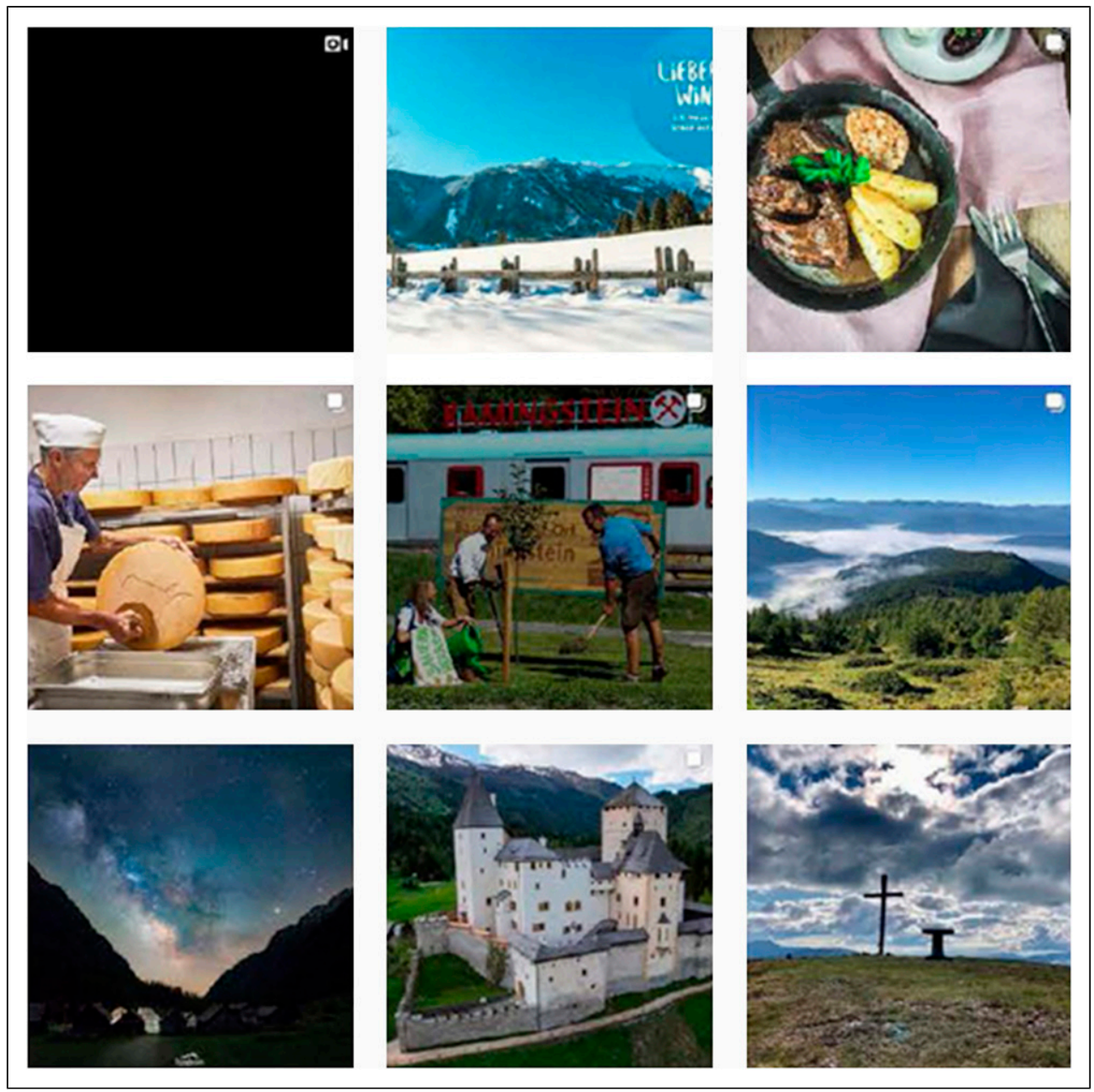

Figure 3. Instagram feed of Salzburger Lungau (https://www.instagram.com/salzburger_lungau/).

Even when you are on holiday, you cannot get away from home. Before mobile phones became so common, you would only find out what had happened, when you got back home" (interview alpine cabin manager).

Interestingly, this theme was repeatedly addressed in the interviews, yet there were few images that showed people spending time together or having conversations. However, this might be due to the timing of data gathering with COVID-19 restrictions in place. Nevertheless, individuals alone in nature, all by themselves, was such a recurrent and dominant theme, that social distancing alone cannot explain the difference.

All dimensions outlined above share a common element of temporariness, they are not intended to induce a permanent transition but rather a transitory stage, which allows one reconnect with nature, self, and others in a more meaningful way. Rather than permanent abstention the utmost goal of disconnection practices as a lifestyle element is to allow for a more deliberate conscious and mindful use of social media or digital technologies once back online. This resonates with Jennifer 
Rauch's (2018) writing on mindfulness and mindful media use: In the Western context, mindfulness has been transformed from a religious and spiritual application to "a secular one where people seek practical insight, therapeutic benefit, and pleasurable engagement" (Rauch, 2018: 97). Mindful media use is often associated with "greater awareness" and less "mindless automaticity" in usage of media technologies, apps, or platforms (Baym et al., 2020: 5). Mindfulness in that sense refers to the "basic human capacity to regulate attention" (Rauch, 2018: 82), and to deliberately target activities and relationships worth our finite time resources.

Earlier studies have shown that indeed only a minority of people who decide to quit Facebook or other social media platforms do so permanently. Most of them return after a hiatus. Franks and colleagues (2018) in their research on disconnecting and reconnecting with social networking sites use the notion of the sabbatical to describe a cyclic recurrence of periods of connection and use and period of abstention from the platform to find relief from technostress, and feelings of being overwhelmed through the purported permanence of exposure to online connectivity. Similarly, we see a deliberate yet temporary abstention from mobile phones and media more generally as an indicator for a supposedly "worthwhile" holiday. The perspective of tourism professionals and the marketing material presented on websites and social media feeds is nostalgic in the sense that there is a return, a reconnection, and a re-discovery of something more meaningful than could be found in everyday life. Nostalgia in that sense is for a better, more profound, and authentic (social) experiences that are contrasted to modern and highly mediated lives.

\section{Disconnection as part of hyperconnected life}

Natale and Treré (2020) suggest to not refuse but complexify our everyday interactions with digital media. This article wants to contribute to the debate and provide more nuanced insights into spaces and times of disconnection. Based on the findings presented, we argue that it is not only disconnection that helps better understand digital culture and living in deeply mediatized societies, but that also comprehending the aspirations of what would be attainable on the other side, so to speak. What do people do, find, and experience when they choose to disconnect or at least use digital devices in a more deliberate way?

The findings of this research project point toward connecting to nature and creating more meaningful and significant connections to the self and others. At the same time, this is not a lonely endeavor by one person wanting to disconnect. Instead, it is seen as an experience that tourism professionals in the Salzburger Land purposefully aim to encourage and create for visitors and guests. Generally speaking, Austria is a highly mediatized society and the tourist industry strongly relies on mediated booking systems and (online) marketing. While there has not been a strong demand for "digital detox" offers, guests disconnecting or adjusting their media use is conceived as an indicator for a "successful" holiday experience. Given the temporal limit of a holiday, we see that phases of disconnection are therefore built into the regular day-to-day experience of a mediasaturated life. Disconnection, therefore, is not an obscure place outside of hyperconnected societies. It does not stand in opposition to, but is integrated into everyday life as an indication and option of alternative lifestyles. In this regard, our study can show that understanding digital disconnection requires a twofold perspective. On the one hand, as previous studies have extensively done, to investigate the motives for disconnection and the pressures people wish to escape for their own benefit. On the other hand, also looking into the alternatives and the fantasy worlds, desires and dreams that are commodified as the where to turn to and what else to do must be studied. As our findings demonstrate it can be specifically the contents and visions, that do not revolve around 
digital disconnection or detox, which best inform what kind of experiences are promoted as an alternative to digital connection.

The presented case focused on tourism and the perspectives of tourism professionals. In their endeavor to create opportunities for experiencing alternatives to being digitally connected, they neglect representations of connection but are also not explicitly advocating for disconnection. Instead, they point to activities away from digital and what else can be done. To us, this is a major take away from this study. Previous research into the why's and how's of disconnection was disconnection-centric in a way. It was about motives for disconnection, representations of disconnection using explicit labels and hashtags to identify the relevant contents. Our findings suggest that comprehending disconnection also demands for a non-disconnection-centric perspective on practices of disconnection and to rather focus on the manifold of alternatives that are suggested. To further advance disconnection research, it might also be fruitful to investigate other realms of everyday life - such as family life, work, and leisure activities — and continue to add more nuanced insights into practices of connection and disconnection. This includes other instances of how disconnection is commodified and what alternate visions for an attainable life without media are presented in doing so, but also such areas and contexts where disconnection is still the norm and not the luxurious alternative. Advancing disconnection research requires an integrated understanding of the high hopes and imaginaries for disconnected times, but also the blank reality of connected and disconnected lives in and outside of the spotlight.

\section{Declaration of Conflicting Interests}

The author(s) declared no potential conflicts of interest with respect to the research, authorship, and/or publication of this article.

\section{Funding}

The author(s) received no financial support for the research, authorship, and/or publication of this article.

\section{ORCID iD}

Christian Schwarzenegger (iD https://orcid.org/0000-0003-1118-9948

\section{References}

Ali F (2015) Heritage tourist experience, nostalgia, and behavioural intentions. Anatolia 26(3): 472-475. DOI: 10.1080/13032917.2015.1013477.

Allcott H, Braghieri L, Eichmeyer S, and Gentzkow M (2020) The welfare effects of social media. American Economic Review 110(3): 629-676. DOI: 10.1257/aer.20190658.

Baym NK, Wagman KB, and Persaud CJ (2020) Mindfully scrolling: Rethinking Facebook after time deactivated. Social Media + Society 6(2): 1-10. DOI: 10.1177/2056305120919105.

Boym S (2001) The Future of Nostalgia. New York, NY: Basic Books.

Bucher T (2020) Nothing to disconnect from? Being singular plural in an age of machine learning. Media, Culture \& Society 42, 610-617. DOI: 10.1177/0163443720914028.

Christou P, Farmaki A, and Evangelou G (2018) Nurturing nostalgia?: A response from rural tourism stakeholders. Tourism Management 69: 42-51. DOI: 10.1016/j.tourman.2018.05.010.

Christou PA (2018) Tourism experiences as the remedy to nostalgia: Conceptualizing the nostalgia and tourism nexus. Current Issues in Tourism 23(5): 612-625.

Cooper D (1994) Portraits of paradise: Themes and images of the tourist industry. Asian Journal of Social Science 22: 144-160. 
Creighton M (1997) Consuming rural Japan: The marketing of tradition and Nostalgia in the Japanese travel industry. Ethnology 36(3): 239. DOI: 10.2307/3773988.

Dann GMS (1997) Tourism: The nostalgia industry of the future. In: WF Theobald (ed) Global Tourism: The next Decade. Reprinted. Oxford: Butterworth-Heinemann, 55-67.

Dickinson JE, Hibbert JF, and Filimonau V (2016) Mobile technology and the tourist experience: (Dis) connection at the campsite. Tourism Management 57: 193-201. DOI: 10.1016/j.tourman.2016.06.005.

Egger I, Lei SI, and Wassler P (2020) Digital free tourism - An exploratory study of tourist motivations. Tourism Management 79: 104098. DOI: 10.1016/j.tourman.2020.104098.

Fish A. (2017). Technology retreats and the politics of social media. tripleC: Communication, Capitalism \& Critique. Open Access Journal for a Global Sustainable Information Society 15: 355-369.

Fürst S, Jecker C, and Schönhagen P. (2016) Die qualitative Inhaltsanalyse in der Kommunikationswissenschaft. In: S Averbeck-Lietz and M Meyen (eds) Handbuch nicht standardisierte Methoden in der Kommunikationswissenschaft. Wiesbaden: Springer VS, pp. 209-225.

Franks J, Chenhall R, and Keogh L (2018) The Facebook sabbatical as a cycle: Describing the gendered experience of young adults as they navigate disconnection and reconnection. Social Media + Society 4(3): 205630511880199. DOI: 10.1177/2056305118801995.

Gomez R, Foot K, Young M, Paquet-Kinsley R, and Morrison S (2015). Pulling the plug visually: Images of resistance to ICTs and connectivity. First Monday 20. DOI: 10.5210/fm.v20i11.6286.

Hardey M and Atkinson R (2018) Disconnected: Non-users of information communication technologies. Sociological Research Online 23(3): 553-571. DOI: 10.1177/1360780418764736.

Hesselberth P (2018) Discourses on disconnectivity and the right to disconnect. New Media \& Society 20, 1994-2010. DOI: 10.1177/1461444817711449.

Jorge A (2019) Social media, interrupted: Users recounting temporary disconnection on Instagram. Social Media + Society 5(4): 205630511988169. DOI: 10.1177/2056305119881691.4.

Karppi T (2018) Disconnect: Facebook's Affective Bonds. Minneapolis: University of Minnesota Press.

Katelieva M, Muhar A, and Penker M (2020) Nature-related knowledge as intangible cultural heritage: Safeguarding and tourism utilisation in Austria. Journal of Tourism and Cultural Change 18(6): 673-689. DOI: $10.1080 / 14766825.2019 .1693581$.

Kaun A and Schwarzenegger C (2014) 'No media, less life?' Online disconnection in mediatized worlds. First Monday 19.

Kaun A and Treré E (2020) Repression, resistance and lifestyle: Charting (dis)connection and activism in times of accelerated capitalism. Social Movement Studies 19(5-6): 697-715. DOI: 10.1080/14742837.2018. 1555752 .

Keller M (2016) Experienced mood and commodified mode. Forms of nostalgia in the television commercials of manner. Medien \& Zeit 31(4): 61-71.

Kelley S (2009) 'Where Hip meets Habsburg': Marketing the personal story in contemporary Vienna. Modern Austrian Literature 42.2: 61-76.

Leaver T, Highfield T, and Abidin C (2020) Instagram: Visual Social Media Cultures. Cambridge, UK; Medford, MA, USA: Digital media and society seriesPolity.

Li J, Pearce PL, and Low D (2018) Media representation of digital-free tourism: A critical discourse analysis. Tourism Management 69: 317-329. DOI: 10.1016/j.tourman.2018.06.027.

McDonnell S (2018) Selling "sites of desire": Paradise in reality television, tourism, and real estate promotion in Vanuatu. The Contemporary Pacific 30(2): 413-435. DOI: 10.1353/cp.2018.0033.

Menke M and Schwarzenegger C (2016) Media, communication and nostalgia. Finding a better tomorrow in the yesterday?. Medien \& Zeit 31(4): 2-6.

Morrison S and Gomez R (2014) Pushback. Expressions of resistance to the 'evertime' of constant online connectivity. First Monday 19(8): 8. 
Natale S and Treré E (2020) Vinyl won't save us: Reframing disconnection as engagement. MediaCulture \& Society, 42: 626-633. DOI: 10.1177/0163443720914027.

Niemeyer K and Keightley E (2020) The commodification of time and memory: Online communities and the dynamics of commercially produced nostalgia. New Media \& Society 22: 1639-1662. DOI: 10.1177/ 1461444820914869.

Pentzold C, Konieczko S, Osterloh F, and Plöger AC (2020) \#qualitytime: Aspiring to temporal autonomy in harried leisure. New Media \& Society 22(9): 1619-1638. DOI: 10.1177/1461444820913566.

Rauch J (2018) Slow Media: Why 'Slow' Is Satisfying, Sustainable, and Smart. New York, NY: Oxford University Press.

Schwarzenegger C and Menke M (2020) Who are the new men in grey? Making sense of time, time-theft and temporal autonomy in the (non)use of digital media. In: A Kaun, C Pentzold, and C Lohmeier (eds) Making Time for Digital Lives: Beyond Chronotopia. Lanham: Rowman \& Littlefield, pp. 63-81.

Selwyn N (2003) Apart from technology: Understanding people's non-use of information and communication technologies in everyday life. Technology in Society 25(1): 99-116. DOI: 10.1016/S0160-791X(02) 00062-3.

Shaw G (1992) Culture and tourism: The economics of Nostalgia. World Futures 33(1-3): 199-212. DOI: 10. 1080/02604027.1992.9972282.

Smith M and Puczkó L (2015) More than a special interest: Defining and determining the demand for health tourism. Tourism Recreation Research 40(2): 205-219. DOI: 10.1080/02508281.2015.1045364.

Sutton T (2017) Disconnect to reconnect: The food/technology metaphor in digital detoxing. First Monday 22. DOI: $10.5210 / \mathrm{fm} . v 22 \mathrm{i} 6.7561$.

Syvertsen T (2020) Digital Detox: The Politics of Disconnecting. Bingley: Emerald Publishing.

Syvertsen T and Enli G (2019) Digital detox: Media resistance and the promise of authenticity. Convergence: The International Journal of Research into New Media Technologies 26: 1269-1283. DOI: 10.1177/ 1354856519847325.

Viallon P (2016) Mediensemiotik. 24 Kriterien für die Bildanalyse. In: S Averbeck-Lietz and M Meyen (eds) Handbuch nicht standardisierte Methoden in der Kommunikationswissenschaft. Wiesbaden: Springer VS, pp. 273-287.

Vorderer P, Hefner D, Reinecke L, et al. (eds), (2018) Permanently Online, Permanently Connected: Living and Communicating in a POPC World. New York ; London: Routledge, Taylor \& Francis Group.

Wacker A and Groth A (2020) Projected and perceived destination image of tyrol on Instagram. In: J Neidhardt and W Wörndl (eds) Information and Communication Technologies in Tourism 2020. Cham: Springer International Publishing, pp. 103-114. DOI: 10.1007/978-3-030-36737-4_9.

Wenger A (2008) Analysis of travel bloggers' characteristics and their communication about Austria as a tourism destination. Journal of Vacation Marketing 14(2): 169-176. DOI: 10.1177/1356766707087525.

Ytre-Arne B, Syvertsen T, Moe H and Karlsen F (2020) Temporal ambivalences in smartphone use: Conflicting flows, conflicting responsibilities. New Media \& Society 22: 1715-1732. DOI: 10.1177/ 1461444820913561. 